\section{Balancing Mathematics Education Research and the NCTM Standards}

Bharath Sriraman (USA)

Michelle Pizzulli (USA)

\begin{abstract}
The release of the Principles and Standards for School Mathematics in the United States by the National Council of Teachers of Mathematics (NCTM) brought to the forefront the debate of whether research should determine the validity of the espoused Standards? Or conversely whether the Standards should influence the research agenda of the mathematics education community? How should university teacher educators address this issue? Should pre-service and practicing teachers blindly accept the Standards as well as the research, or do we cultivate the critical thinking skills that will allow preparing teachers to resolve this dilemma? In this article a university mathematics educator and an idealistic pre-service elementary teacher try to resolve the dilemma of balancing the Standards with research and personal beliefs about the teaching and learning of mathematics.
\end{abstract}

Kurzreferat: Die Veröffentlichung der Prinzipien und Standards für Schulmathematik in den Vereinigten Staaten durch den National Council of Teachers of Mathematics (NCTM) brachte im Vorfeld die Debatte ins Rollen, ob die Forschung die Gültigkeit der befürworteten Standards determinieren sollte. Oder im Gegenteil, ob die Standards die Forschungsagenda der Mathematikdidaktiker beeinflussen sollte. Wie würden die universitären Ausbilder von Mathematiklehrern mit dieser Fragestellung umgehen? Sollten zukünftige und bereits praktizierende Lehrer diese Standards ebenso blind akzeptieren wie die Forschung, oder kultivieren wir kritisches Denken, welches die Lehrer darauf vorbereitet, dieses Dilemma zu lösen? In diesem Artikel versuchen ein universitärer Mathematiklehrerausbilder und ein idealistischer Lehrer in der Ausbildung dieses Dilemma zu lösen, indem sie die Standards mit der Forschung und persönlichen Beliefs über das Lehren und Lernen von Mathematik ausbalancieren.

\section{ZDM-Classification: C60}

\section{Introduction}

The Principles and Standards for School Mathematics ${ }^{1}$, a publication of the National Council of Teachers of Mathematics (NCTM, 2000), provides an ideal vision of the mathematical content and processes that are relevant in the $21^{\text {st }}$ century. The strand for elementary students revolves around five overarching basic goals, which are to help students cultivate number sense, methods of estimation and measurement, pattern recognition, geometric concepts, and statistical methods. It is laudable that these overall goals remain the same as a student progresses from the early elementary level to the late high school level while the depth of investigation within a particular content domain increases. It makes perfect sense to introduce concepts early in an intuitive manner, and to build on these as students' reasoning abilities

${ }^{1}$ Referred to as the Standards in the remainder of the paper. mature. The NCTM sets high standards for students at all levels to measure up to. The agenda set for the elementary level (Kindergarten - Grade 5) is challenging especially in the realm of geometry where students are expected to construct convincing arguments and proofs to solve problems and/or draw conclusions about geometric figures and patterns. In essence by placing primary responsibility for establishing the validity of mathematical ideas with the students, the Standards are viewing each student as a mathematician. Having students justify the validity of their ideas promotes the importance of being able to communicate with others by organizing arguments in a coherent way. How are teachers, especially those that are new to the profession supposed to achieve the high expectations on learning outcomes set by the Standards? Shouldn't classroom pedagogy also take into account the current research on teaching and learning? Are the Standards and Research mutually exclusive? Or can they be harmoniously balanced? These are the topics of exploration in this paper.

\section{A Pragmatic View of Standards and Research}

Standards are statements about what is most valued, so they need not be justified by research although some of the statements are backed by research (Hiebert, 1999). Most mathematics educators' position is that research can inform this debate but is not a necessary condition. Research cannot prove what is "best". Human judgement has to decide what is "best". The best example is the use of calculators in the classroom. Some of the most brilliant ideas in mathematics and the sciences have come out of intuition. Hiebert (1999) says that the research process can help one see things differently and imagine new possibilities. Research is helpful in documenting the effectiveness or the ineffectiveness of new ideas and can suggest explanations for successes and failures. Research can help document the current state of teaching in the classroom, the curricular materials being used, and how students are learning.

One of the jokes among mathematics educators in the US is: if Benjamin Franklin were to miraculously appear in the world today, he would be unable to cope with all the changes that have occurred. However he would surely recognize a classroom because of the consistent way in which school subjects are taught! Research in mathematics education has shown that the mode of instruction has been consistent even in the face of reform. The routine followed in most traditional mathematics classrooms are: solutions to the previous days homework, short presentation of the next topic, followed by seat work, during which the teacher moves about the classroom answering questions (Fey, 1979; Hiebert,1999 ; Stigler \& Hiebert, 1997). Emphasis on procedures and the classroom routine just mentioned are the defining characteristics of most mathematics classrooms. The history of reform in the United States has shown that the main reasons why promising alternative programs fail are: (1) They aren't implemented effectively when adopted by schools and districts; (2) They are not given enough time to truly assess whether they are successful or 
not; (3) Lack of teacher preparation., and (4) Lack of documentation of how alternative programs are being implemented in the classroom.

\section{The Hidden Role of Beliefs}

New programs expect teachers to make over night changes in their mode of classroom instruction. Reform does not happen readily, since teachers look through old lenses, and if teachers' beliefs don't change, neither will their methods. In subscribing to a constructivist view of mathematics teaching and learning the NCTM Standards envisions classrooms in which students learn mathematics as they construct ways of dealing with problematic situations. They do this by reflecting on their interactions with the world and their peers, and their attempts to make sense of those interactions. This vision of the Standards is unlikely to become reality if teachers still view themselves in the traditional role of transmitter (and authorities) of knowledge.

Ernest (1989) categorized three philosophies of mathematics, namely the instrumentalist view, the Platonist view, and the problem solving view. The instrumentalist sees mathematics as a collection of facts and procedures, which have utility. The Platonist sees mathematics as a static but unified body of knowledge. Mathematics is discovered, not created. The problem solving view looks on mathematics as continually expanding and yet lacking ontological certainty. The problem solving view sees mathematics as a cultural artifact. This implies that what is thought as true today, may not be seen as true tomorrow (pp. 99-199). Ernest also describes absolutist and fallibilist views of mathematical certainty. The absolutist sees mathematics as completely certain and the fallibilist recognizes that mathematical truth may be challenged and revised (Ernest, 1991, p.3). Lerman (1990) recognizes that ones philosophy is related to ones preferred teaching style. The absolutist teacher will prefer a direct teaching style whereas a fallibilist is much more likely to engage in exploratory activities and open-ended problems.

Thompson (1984) studied three middle school teachers, all of whom had different beliefs about the nature of mathematics. The first teacher viewed mathematics as a coherent collection of interrelated concepts and procedures. She regarded mathematics as a subject free of ambiguity and emphasized conceptual development in the students. She would fit Ernest's model as a Platonist. The second teacher had a very different perspective of mathematics and her teaching reflected more of a process-oriented approach than a content oriented approach. A view of mathematics as a subject that allows for the discovery of properties and relationships through personal inquiry seemed to underlie her instructional approach. This teacher viewed problem solving as the fundamental goal of learning and regarded mathematical notation as arbitrary. She would fit Ernest's model as person with the problem solving view. The third teacher in Thompson's study saw mathematics as a collection of facts and procedures, which help students' find the answer. She saw no ambiguity in mathematics. She would fit Ernest's model as a person with an instrumentalist view. Thompson sees at least three distinct ways of viewing mathematics, all of which greatly influence the choice of curriculum and its delivery. Thompson (1992) says that research on teachers cognitions, studies of teachers' conceptions have contributed to a conceptual shift in the field of research on teaching, moving away from a behavioral conception of teaching towards "a conception that takes account of teachers as rational beings” (p.142). Our understanding of teaching from teachers' perspectives complements our growth of understanding of learning from learners' perspectives, which in turn, enriches the idea of schooling as the negotiation of norms, practices and meanings (Cobb, 1988).

\section{Implications for Elementary School Mathematics Educators}

In the U.S, many pre-service elementary teachers take a two-semester sequence of mathematics content courses at the university level. This is followed by generic methods courses. As a mathematics educator at the university, one has the heavy responsibility of making sure that preservice elementary teachers understand the elementary mathematics content and feel confident enough to teach it using alternative modes of instruction such as guided discovery as opposed to direct instruction. In addition pre-service elementary school teachers should also be familiarized with the local and national standards as well as periodicals that will help them as practitioners in the elementary classroom. Ideally teachers will be able to find the right balance between what the research suggests are the best ways of learning and teaching and standards that suggest what the ideal outcomes ought to be. In the remainder of this paper, a pre-service elementary teacher (Michelle Pizzulli: the second author) takes on the arduous task of balancing the research with the standards and designing an instructional approach that is also compatible with her beliefs about the teaching and learning of mathematics. This narrative is left in the first person in order to allow the reader to form an appreciation of the types of decision making involved in planning a geometry lesson. It also assumes that the reader is vaguely familiar with the Geometer's Sketchpad, a dynamic geometry software that is commonly found in computer labs at educational institutions and geo-boards, a useful physical manipulative to teach geometric concepts.

\section{Designing an Ideal Lesson in Area: Michelle’s journey}

\section{What am I trying to teach?}

I would like to teach concepts of measurement to fifth graders. In particular, the students will be able to calculate the area of a variety of polygons using geoboards and by utilizing the dynamic geometry software program Geometer's Sketchpad (GSP). In calculating area, students will practice and apply mathematical skills previously learned such as multiplication. Although we may not realize it, an understanding of area and spatial reasoning is very 
applicable in everyday life, such as building a tree fort, parking a car, or finding room for a new piece of furniture or rug.

\section{What do the Standards say?}

The NCTM emphasizes the importance of geometrical reasoning at all grade levels. In particular, my lesson focuses on enabling all students to use visualization, spatial reasoning and geometric modeling to solve problems. The students will fulfill the standards by drawing geometric objects using Sketchpad and use geometric models to solve problems in other areas of mathematics, in particular measurement. The activities in my lesson pose worthwhile mathematical tasks to the students. These activities engage the students and are challenging. They develop the student's mathematical understanding and skills, and stimulate students to make connections between area formulas of many different polygons. Since I ask the students to discover the formulas on their own, rather than tell them the formulas, they are involved in mathematical reasoning. While finding the formulas, students will use a variety of tools such as Geoboards and Geometer's Sketchpad to reason and make connections and solve problems. They will make conjectures, present solutions, and rely on mathematical evidence to determine validity of these solutions. While students work, I will be observing, listening to and gathering information about the students to assess what they're learning. This will ensure that each student is being challenged, yet not struggling, and help me decide if any adaptations or changes need to be made to the lesson.

\section{What does the research say?}

In preparing this lesson, I did some research on the importance of geometry in the curriculum, as well as the involvement of technology in the teaching of mathematics, in particular the use of dynamic geometry software. I found a variety of articles supporting my beliefs that we must not leave geometry on the back burner, and that the use of technology can be exciting while at the same time enhance a student's understanding of geometry.

Shannon (2002) discusses the lack of geometry being taught in schools today. He recognizes it as a big problem, stating that "currently, there is less geometry being taught in schools than at any time since the Middle Ages..."(p.26). Shannon says this could possibly be due to the perception that geometry "has little relevance in modern society”(p.26). However, geometry is incredibly important and applicable in many work situations as well as in every day life. In his article, Shannon discusses spatial awareness and understanding, which directly relates to my topic of study, area. Since we live in a spatial environment, and much of what we do requires spatial reasoning, the study of geometry is extremely important and should not be left behind in today's curriculum.
Scher (1999) poses the question, "Can dynamic geometry software be used for proofs as well as a demonstration tool?" At first glance it might appear that programs such as Geometer's Sketchpad only provide a demonstration, leaving the user clueless as to why something occurs in geometry. Must we just accept a theorem for true without having any proof to back it up? Scher (1999) suggests that such dynamic geometry software packages offer the tools to jumpstart ideas that lead to a proof. They can demonstrate things (i.e. movement) that a physical model is not able to show. The use of the tools and functions in these software programs influence how we reason mathematically. I used some of these thoughts when creating my lesson plan on the area of polygons. Rather than just give the students a formula to accept as true, I had them come up with the formulas of certain polygons using Sketchpad. This way they were able to see why something worked, which in the end results in real learning, rather than just memorization.

Wilson (1999) discusses the need for teachers to familiarize themselves with and become comfortable with new forms of technology for the classroom, in particular dynamic geometry software. Teachers who have not been trained on such programs might be afraid or unwilling to use them. This is unfortunate considering the benefits these programs have to offer in teaching important subjects such as geometry. Wilson notes that many of the activities are quite exciting for teachers, and most definitely for the students. I can attest to that. I'm sure my math professor has heard me "wowing" over something really neat that I've just discovered on Sketchpad. Also, these programs are fairly easy to use, requiring little help from the teacher. Therefore, he or she may be available to answer any of the student's needs, rather than walking them through it step by step. In today's age of increasing technology, it is important to prepare students to use a variety of computer programs. However this is only possible if the teachers themselves are comfortable with the programs. Fortunately, Math 131 is doing a good job in preparing us to bring these tools into our classrooms. I even felt confident enough to write up some of my own Sketchpad labs to use in the classroom.

Clements and Lindquist (2001) state that the geometry standard is included as one of the five content standards for mathematics. That means it is just as important as the others, and it is the teacher's responsibility to provide opportunities for learning and using geometry. They talk about using geometry to investigate, make conjectures and developing logical arguments to justify conclusions. This is exactly what my lesson is based on. I ask my students to explore area, make conjectures on the area of a variety of polygons, and derive the formulas themselves. The article discusses the importance of recognizing how one shape may be made up of other shapes. My students will see how a parallelogram is actually made up of a rectangle of the same area. They will use this information to determine the formula for area of a parallelogram. They will do several other activities relating the area of one shape to determine the area of another. In this way geometry is used as a tool to 
foster reasoning, for the students will see where the formula comes from rather than just blindly accepting it.

Romagnano (1994) writes about two completely different methods of teaching. The first is to simply give your students a problem and tell them exactly how to go about it, allowing them no room to make inferences of their own. The second method involves posing a problem to the class and allowing them to go about it in any way they wish to arrive at the answer. Romagnano (1994) discusses how each of these methods has its benefits and downfalls. The "tell-them" method, while providing the students the means of arriving at the correct answer, requires no mathematical reasoning. The students can perform the task correctly, however they don't know why the answer is so. The "ask-them" method did involve students in the process of the problem, however the absence of guidelines often left them struggling and frustrated. Some students weren't getting much out of this method, even though they were actively engaged in the problem. Somewhere, a middle ground must be reached, where the students are asked to come up with solutions with some guidelines from the teacher. This is exactly what I aim to do in my lesson. I do not give the formulas to the students for memorization, rather I ask them to tell me the formulas. However, I give them fairly specific guidelines to follow to help them in the process. I believe that with the lessons I've created, each student will have the opportunity to think and reason on their own and be challenged, yet not be left behind.

\section{The Lesson}

A Lesson In Area is a three-day lesson in which the students will explore the areas of a variety of polygons. It utilizes the use of technology as well as other manipulatives in the math classroom. Following the NCTM Standards, the lesson requires that students use visualization, spatial reasoning and geometric modeling to solve a problem. The first day I simply introduce the concept of area, and we practice finding the area of a variety of polygons using the geoboards. Students will discover how to easily find the area of a rectangle and come up with the formula. This will be the basis for what we do later in sketchpad. Day two we will go to the lab and use Geometer's Sketchpad to discover formulas for the area of a parallelogram and a triangle. Finally, on day three, we will continue in the lab, using our previous knowledge to determine area formulas for a trapezoid and hexagon. These are the very first Sketchpad labs I've written myself and I am quite proud of them. Here goes...

\section{Day One}

I will introduce the topic of area: "We know that perimeter is the distance around a closed curve, but what if we wish to know how much space is inside that region? The measurement of all the space inside a region is called area. We use special formulas to find the area of different types of polygons, but before we get into that we will try to find the area of some polygons using geoboards."

Hand out geoboards, rubber bands and worksheet with simple polygons to model. I will have the students find the area of a square and a rectangle by counting how many "square units" it is made up of. I will ask them if they know of a quicker way to do it, then suggest they multiply one side by an adjacent side and see what they get. Is it the same? Then I will have them work on more complex polygons (parallelograms, trapezoids, triangles, even concave polygons). I will first let them experiment without telling them how to go about finding the area. Students may work in small groups at their tables to brainstorm. I will ask for any ideas, and if nobody gets it I will model two methods of finding area using the geoboards. The first, the addition method, involves breaking up the polygon into smaller pieces in which the area is easily determined, and then adding up the sum of those smaller areas. The second, rectangle method, involves constructing a large rectangle that contains the entire polygon, finding the area of the rectangle, then subtracting the number of square units making up the polygon. I will have the students find the area of a number of different polygons using both of these methods, and at this time I will stroll around the classroom answering questions and providing helpful suggestions/hints.

\section{Day Two}

We will spend this day in the lab. At the beginning of class I will ask the students if they remember how to calculate the area of a rectangle. Then I will tell them that the area of a parallelogram can be found by finding the area of a rectangle. They will open up Geometer's sketchpad and:

Construct a parallelogram and starting with the top left corner label its vertices clockwise, ABCD.

Now, draw a line perpendicular to line DC that passes through point A. Also draw a line perpendicular to line DC that passes through point B. Do you notice how it creates a rectangle?

Now you can find the measurement by using the formula: $\mathrm{A}=$ base $\mathrm{x}$ height. The base is the bottom (or top) side of the parallelogram and the height is either of the perpendicular segments you drew in step two (distance between the two bases). Calculate those measurements, base and height, and then multiply them. This is the area of your parallelogram.

Open a new sketch. Construct a triangle. The area of a triangle can be found using the area of a parallelogram constructed from two congruent triangles.

Find the midpoint of one side. Select the entire triangle and mark the midpoint. Go to the Transform menu and choose Rotate. Rotate the triangle 180 degrees about that midpoint. What type of polygon does this give you?

Now you can use the formula for the area of a parallelogram to find the area of the triangle. *Be careful: The triangle is truly only half the area of the parallelogram. Be sure to adjust your formula accordingly. What is the formula for the area of a triangle? 


\section{Day Three}

We will be in the lab again today, continuing the study of area using geometer's sketchpad.

Construct a trapezoid and label it starting with the upper left hand corner, going clockwise, ABCD.

Draw a segment from point $A$ to $C$. What does this give you? Can you find the area of a trapezoid using the area of two triangles?

Find the area of each triangle. You will need to find the height by drawing a line through point $A$ that is perpendicular to DC. Remember, the formula for area of a triangle is

$A=1 / 2$ base $x$ height.

Add the areas of the two triangles and the sum is the area of the entire trapezoid.

What is the formula for area of a trapezoid, then? Use the distributive property to simplify the formula.

Open a new sketch. Can we find the area of a regular hexagon by dividing it into congruent triangles? Create segment AB. Go to the transform menu, mark center A.

Select segment $\mathrm{AB}$ and its endpoints. Go back to the transform menu and choose to rotate the segment 60 degrees. Continue to rotate until you have a total of six mini-segments, or "spokes". Connect the endpoints to make a regular hexagon.

The height of a triangle of a regular polygon is called the apothem, a. Draw the apothem using a perpendicular bisector of one of the sides, which passes through the center of the hexagon.

The area of each triangle is $1 / 2$ (apothem $x$ side). Use the measurement of the side which is also an edge of the hexagon. Find the area of one of the triangles.

Now what do you do to find the area of the entire hexagon? Remember, there are six triangles contained in the hexagon. What is the formula for the area of a regular hexagon?

What would be the formula for a regular n-gon?

\section{Reflections}

When reading some of the articles, I realized just how important geometry is in everyday life. It is vital that we, as teachers, provide our students with a strong basis in geometry if they are to be good spatial thinkers. So many of the things we do rely on basic knowledge of geometry concepts. In writing my lessons, I wanted my students to actually learn something, instead of just regurgitating formulas they have been given. So I asked them to figure out the formulas on their own, using mathematical reasoning. I hope that this will make the concept of area clearer and more permanent. When we just give students information to memorize and recall, they are not actually learning anything. I hope that "A Lesson In Area” will stimulate the students' brain activity and refine their skills in problem solving, mathematical thinking and spatial reasoning. Then, hopefully they will take these skills with them and apply them to everyday situations.

The lessons presented here I believe are quite challenging to the students, even those who are gifted. They require a lot of thinking and problem solving. However, I could add some more problems on to the lessons for more talented math students. I could have them find the area of a more complex polygon, even a concave polygon. They could do this by breaking the concave figure up into recognizable convex polygons and find the area of each region, then add those up. Or I could alter their lab activity to allow for more free-thinking. For instance, rather than give them step by step directions on how to create a regular hexagon by rotating a segment by 60' repeatedly, I could ask them how they think we should do it. I am a huge supporter of having the students learn as much as possible from themselves or each other, rather than from the teacher. I feel they get more out of the lesson if they are actively involved in the process as a pose to passively taking in information.

\section{Conclusions and Implications}

Having presented the active voice of a pre-service teacher trying to design a lesson that balances the Standards with mathematics education research several things are evident. (1) It is evident that balancing the research with the Standards is no easy task and involves a great deal of planning, commitment and self reflection on the teachers part, as evidenced in Michelle's passionate attempt to design an ideal lesson. (2) It is also clear that the type of instructional unit designed is a function of the teacher's beliefs about the teaching and learning of mathematics. Michelle's lesson reflects her beliefs about mathematics, as a subject that allows for the discovery of properties and relationships through personal inquiry. Michelle would fit Ernest's (1991) model as person with the problem-solving view of mathematics.

Michelle's lesson balances the concerns raised by Hiebert (1999) regarding the relationship between research and standards. Hiebert's (1999) position is that standards are statements about what is most valued (p.4) and he further states that research can inform the debate. To Michelle the Standards conveyed the message that mathematics should be taught with an emphasis on understanding, an interpretation that was compatible with her beliefs about the teaching and learning of mathematics. The survey of research indicated to her that geometry had numerous real-world applications, which was again harmonious with her problem-solving approach to teaching mathematics.

It must be pointed that Standards are open to individual interpretation and there is always the possibility that some teachers might interpret them as teaching procedures. Since research has informed us about what students do not comprehend in geometry and eventually in proof writing, it would make more sense to guide students into discovering geometry and proof the way mathematicians do. Deductive proof is the outcome of a process and not the starting point (Fawcett, 1938, Senk, 1985, Usiskin, 1987). 
The idea of building up directly on students' knowledge as they progress from the elementary to higher levels, as espoused by the Standards is brilliant. The authors hope that elementary classroom teachers will find the right balance between research and standards as they help their students further their ability to read, write and discuss mathematics and provide them with an opportunity for discovery and invention.

\section{References}

Clements, D \& Lindquist, M. (2001). Geometry must Be vital. Teaching Children Mathematics, Vol. 7, No.7, 409-415.

Cobb, P. (1988). The tension between theories of learning and theories of instruction in mathematics education. Educational Psychologist, 23, 87- 104.

Ernest, P. (1989). The impact of belief on the teaching of mathematics. In C. Keitel,

P.Damerow, A. Bishop \& P. Gerdes (Eds.), Mathematics ,Education, and Society (pp.125-146). Paris: UNESCO Science and Technology. Education Document Series, NO. 35.

Ernest, P. (1991). The Philosophy of Mathematics Education, Briston, PA: The Falmer Press.

Fawcett, H. P. (1938). The nature of proof. Thirteenth yearbook of the NCTM. New York: Bureau of Publications, Teachers College, Columbia University.

Fey, J. (1979). Mathematics teaching today: Perspectives from three national surveys. Mathematics Teacher, 72, 403-434.

Hiebert, J. (1999). Relationships between research and standards. Journal for Research in Mathematics Education, 30, 1, 3-19.

Lerman, S. (1990). Alternative perspectives of the nature of mathematics and mathematics teaching to instructional practice. Educational Studies in Mathematics, 15, 105-127.

National Council of Teachers of Mathematics. (2000). Principles and standards for school mathematics: Reston, VA: Author.

Romagnano, L. (1994). Wrestling with change: The dilemmas of teaching real mathematics. Portsmouth, NH: Heinemann.

Scher, D. (1999). Problem solving and proof in the age of dynamic geometry. Micro Math, vol.15/1, p.24-30.

Senk, S. (1985). How well do students write geometry proofs? The Mathematics Teacher,78, 419-486.

Shannon, P. (2002). Geometry: An urgent case For treatment. Mathematics Teaching, 181, pp.26-29.

Stigler, J.W., \& Hiebert, J (1997). Understanding and improving classroom mathematics instruction; An overview of the TIMMS video study. Phi Delta Kappan, 79(1), 14-21.

Thompson, A. G. (1984). The relationship of teachers conceptions of mathematics and mathematics teaching to instructional practice. Educational Studies in mathematics, $15,105-127$.

Thompson, A. G.(1992): Teachers beliefs and conceptions: a synthesis of the research. In D. A. Grouws (Ed.), Handbook of Research on Mathematics Teaching and Learning (pp. 127146), NCTM. Macmillan Publishing Company: New York.

Usiskin, Z. P. (1987). Resolving the continuing dilemmas in school geometry. In M. M.Lindquist, \& A. P. Shulte (Eds.) Learning and teaching geometry, K-12: 1987 Yearbook (pp. 17-31). Reston, VA: National Council of Teachers of Mathematics

Wilson, A. (1999). In need of a kick start. Micro Math, vol.15/1, p.31-33.

\section{Authors}

Prof. Dr. Bharath Sriraman
Editor, The Montana Mathematics Enthusiast http://www.montanamath.org/TMME

Dept. of Mathematical Sciences,

The University of Montana,

Missoula, MT 59812,

USA.

E-mail: sriramanb@mso.umt.edu

Michelle Pizzulli

The University of Montana 